\title{
Staff perception on reduction of medication in patients with chronic schizophrenia
}

\author{
A. Thomas, G. Katsabouris and N. Bouras
}

This exploratory study assessed staff perceptions to the rectuction of maintenance neuroleptic medication in patients with chronic schizophrenia Iiving in a longstay hospltal. Ten in-patients were assessed at regular times over six months. In addition to the Briet Poychiatric Rating Scale (BPRS), data were obtained from nursing staff on patients' ward behoviour (Ward Behoviour Interview Schedule, WBIS), clinical global opinion (CGI) and staff reaction (SR) to the recluction of medication plan. The average decrease of BPRS and WBIS was not related to keyworker's clinical global impression. The SR increased against the reduction of medication over the study period $(P<0.05)$. Staff perceptions in the treatment of patients with chronic schizophrenia and their poselble Influence on prescribed doses should be taken into consideration in addition to peychopathology and clinical symptoms.

The value of maintenance neuroleptic therapy for patients with schizophrenia has been well documented (Kane, 1987; Soni et al, 1992). There has been, however, a trend in recent years of prescribing higher than recommended doses of neuroleptics in the treatment of schizophrenia (Reardon et al, 1970). This is in agreement with the unconvincing evidence that higher doses of medication present additional benefits to people with chronic schizophrenia (Rifkin et al, 1991). The Royal College of Psychiatrists has issued a consensus statement advising caution in using high doses of neuroleptics (Thompson, 1994). In addition, recent reports have shown that clinical audit projects can result in the reduction of polypharmacy in patients with chronic schizophrenia in hospitals (Warner et al, 1995).

We report the findings of an exploratory study to assess staff perceptions in reducing the maintenance dose of neuroleptic medication in patients with chronic schizophrenia living in a long-stay hospital, before their discharge to community facilities.

\section{The study}

Ten in-patients with chronic schizophrenia, living in a 20-bed, long-stay ward and presenting a stable mental state over a period of one year were included in the study. Each was diagnosed as suffering from paranoid schizophrenia according to DSM-III-R criteria (American Psychiatric Association, 1987), and had no secondary diagnosis. The other patients living in the same ward were excluded because four had serious forensic histories, three suffered from manic-depressive psychosis, two had personality disorders and one had learning disabilities.

The patients included were all being prepared for resettlement into the community and had individually designed 'care plans' meeting their needs as far as possible. A reduction of medication plan was adopted for the study period, with the agreement of the ward team. The aim of the medication reduction was to maintain each patient at the lowest possible dose. Patients who had been maintained on both depot and oral medication would, as far as possible, be maintained on depot neuroleptics alone.

Patients were assessed at the start of the study and at regular intervals over a period of six months. The following measurements were obtained:

(a) the Brief Psychiatric Rating Scale (BPRS; Overall \& Gorham, 1962)

(b) the Ward Behaviour Interview Schedule (WBIS; Blunden et al, 1994), this scale measures patients' behaviour and activities and was completed by interviewing the keyworkers

(c) the keyworker's opinion was recorded on the Clinical Global Impressions scale (CGI; Endicott et al, 1976).

Staff reaction (SR) reflected the keyworkers' negative attitude towards the reduction of medication over the study. This is a 0-3 point self-devised scale rated as: no reaction 
(agreement) $=0$; mild reaction $($ doubt $)=1$; moder ate reaction (negative attitude) $=2$ and strong reaction (strong negative attitude) $=3$.

The statistical procedures employed were those of repeated measures and simple factorial MANOVA and MANCOVA, the Wilcoxon matched-pairs sign test and the bivariate correlation.

\section{Findings}

The sample consisted of eight men and two women. The mean age was 43.7 years (range 28-63) and the mean length of stay 6.6 years.

The mean dose of medication expressed as the chlorpromazine equivalent (Foster, 1989) was reduced from $970 \mathrm{mg}$ (s.d. $=690.9 \mathrm{mg}$ ) daily at the beginning to $399 \mathrm{mg}$ daily (s.d. $=253.5$ ) at the end of the study (Table 1). The rate of dose reduction at each follow-up session ranged from 5 to $20 \%$. The average number of daily neuroleptic drugs decreased from 2.6 to $1.3(50 \%)$ during the study. In one patient the dose had to be increased in the fourth month because of a deterioration in his mental state.

The BPRS. WBIS and CGI were not found to have changed significantly during the study. Bivariate correlation was applied to the means of BPRS, WBIS and CGI for each time-period with correlation coefficients (Table 2).

The SR to the reduction of medication was found to be different at the beginning and at the end of the study (Wilcoxon matched-pairs sign test, $Z=-2.01, P<0.05)$. The mean $S R$ increased from 2.6 to 3.4. The reaction of ward stafi increased against the reduction of the medication, although the CGI itself remained statistically the same over the study period.

A simple factorial ANCOVA (analysis of covariance) was done to detect differences among patients concerning SR.

We used SR as a dependent variable measured seven times (once for each follow-up). Dose was selected as a covariate $(F=0.03, P<0.05)$ because of its strong negative correlation with SR (multiple regression, multiple $R=0.67$, regression
Table 2. Matrix of correlations by Wilcoxon matched-pairs sign test among the means of BPRS, WBIS and CGI

\begin{tabular}{lll}
\hline Correlation & $\boldsymbol{Z}$ & $\boldsymbol{P}$ \\
\hline BPRS-WBIS & 0.79 & 0.022 \\
BPRS-CGI & 0.30 & 0.255 \\
WBIS-CGI & 0.61 & 0.072 \\
\hline
\end{tabular}

coefficient $=-0.001$ ). The SR was found to be significantly different among patients $(F=0.001$, $P<0.05)$. The mean $S R$ was greater for patients having previous offending or self-harm history $(R=2.2)$ than for those without such a history $(R=1.79)$

\section{Comment}

Despite the gradual reduction in the dose of neuroleptic medication in the study, no deterioration in the patients psychopathology was found, at least over the six-month period. These findings are in line with previous studies (Van Putten et al, 1993: Leblanc et al, 1994).

However, the reaction of staff members varied. Staff were clearly apprehensive about the gradual reduction of neuroleptic medication. Staff perception of patients' behaviour was probably influenced by the history of offence and selfharm and not related to their psychopathology. as measured by the BPRS. On several occasions staff expressed reservations about further reduction of medication, despite lack of evidence of deterioration in the patients' mental state. On other occasions minor behavioural manifestations such as 'the patient not getting up on time' or 'refusing to attend activities' were interpreted as possible relapses.

The interpretation of behavioural symptoms as psychotic relapses by ward staff and clinicians has been previously noted (Greenfield et al, 1989). Clinicians are greatly influenced by staff reports in prescribing higher doses of neuroleptic

Table 1. Mean (s.d.) scores for dose, BPRS', WBIS $2, \mathrm{CG}^{3}$ and $\mathrm{SR}^{4}$ obtained in each follow-up

\begin{tabular}{llllllll}
\hline Time & O weeks & 2 weeks & 4 weeks & 6 weeks & 10 weeks & 16 weeks & 24 weeks \\
\hline Dose & $970.00(690.89)$ & $826.00(581.17)$ & $668.00(526.43)$ & $578.00(431.47)$ & $546.00(440.66)$ & $489.00(389.44)$ & $399.00(253.52)$ \\
BPRS & $24.00(7.49)$ & $24.30(8.85)$ & $25.30(7.70)$ & $22.30(4.85)$ & $21.90(4.86)$ & $22.00(5.86)$ & $22.10(5.30)$ \\
WBIS & $11.10(6.31)$ & $10.10(6.24)$ & $10.90(6.70)$ & $9.00(4.87)$ & $9.10(4.99)$ & $9.60(7.05)$ & $10.20(7.31)$ \\
CGI & $8.00(1.15)$ & $8.20(1.47)$ & $8.20(1.31)$ & $7.60(1.17)$ & $7.80(1.39)$ & $8.00(1.49)$ & $8.50(1.08)$ \\
SR & $2.60(1.26)$ & $2.60(1.17)$ & $3.00(0.81)$ & $2.60(1.17)$ & $2.90(0.87)$ & $2.80(0.91)$ & $3.40(0.96)$ \\
\hline
\end{tabular}

1. Brief Psychiatric Rating Scale.

2. Ward Behaviour Interview Schedule.

3. Clinical Global Impressions.

4. Staff reaction. 
medication (Krakowski et al, 1993) and may find it easier to add new medication rather than change ineffective or unnecessary ones given for some time (Holloway, 1988). Previous studies (Edwards, 1982; Muijen \& Silverstone, 1987) suggest that prescription of medication is influenced more by training and the exchange of ideas between doctors than by the presenting symptoms of patients.

In spite of the small number of patients involved in this study the findings indicate the importance of staff perception in the treatment of people with schizophrenia with neuroleptic medication and their possible influence on the prescribed doses. Training of staff, including clinicians, is of the utmost importance, to make them aware of all factors affecting prescribing. This is particularly so at the current time of scarce resources in mental health services, community care and 'managed care', as well as users' participation and public opinion's reservations on psychotropic medication. Studies on the risks of reducing neuroleptics in people with chronic schizophrenia, based only on measuring of their psychopathology without taking into consideration staff perceptions and attitudes, will have only limited value.

\section{Acknowledgements}

We are grateful to all ward staff on Tl Ward, Bexley Hospital and to Dr Maurice Meir, Dr Sue Cope, Carol Paton and Isobel Morris.

\section{References}

Ámerican PSYCHLATRIC ASSOCLATION (1987) Diagnostic and Statistical Manual of Mental Disorders (3rd edn, revised) (DSM-III-R). Washington, DC: APA.

BLUNDEN, J., HODGSKISS. A., KLEMPERER, F., et al (1994) The Ward Dally Behaviour Scale. British Journal of Psychiatry. 165, 87-93.

ENDICOTT, J., SPITZER, R. L.. Fleiss, J. L., et al (1976) The Global Assessment Scale: a procedure for measuring overall severity of psychiatric disturbance. Archives of General Psychiatry. 33. 766-771.

EDWARDS, G. J. (1982) Factors influencing the psychotropic drug choices of teachers of psychiatry. British Journal of Clinical and Social Psychology. 2, 24-26.
FOSTER. P. (1989) The neuroleptic equivalence. Pharmaceutical Journal, 9, 431-432.

GREENFIELD, T., MCNiEL, D. \& BINDER, R. (1989) Violent behavior and length of psychiatric hospitalization. Hospital and Community Psychiatry. 40. 809-815.

HoLloway, F. (1988) Prescribing for the long-term mentally ill: a study of treatment practices. British Joumal of Psychiatry, 162, 511-515.

KANE. J. (1987) Treatment of schizophrenia. Schizophrenia Bulletin. 13, 133-153.

KRAKOWSK. M., KUNZ, M.. CzOBOR. P., et al (1993) Long-term high-dose neuroleptic treatment: who gets it and why? Hospital and Community Psychiatry. 44, 640-644.

Leblanc, G.. CORMiER, H., GAGNe. M. A., et al (1994) Effects of neuroleptic reduction in schizophrenic outpatients receiving high doses. Canadian Journal of Psychiatry. 39. 223-229.

MULEN, M. \& SILVERSTONE. T. (1987) A comparative hospital survey of psychotropic drug prescribing. British Journal of Psychiatry, 160. 501-504.

OVERALL. J. E. \& GORHAM. D. R. (1962) The Brief Psychiatric Rating Scale (BPRS). Psychological Reports, 10, 799812.

REARDON. G. T., RIFKIN, A., SchWARTZ, A., et al (1970) Changing patterns of neuroleptic usage over a decade. American Joumal of Psychiatry. 146. 726-729.

RIFKIN, A., DODDI, S., KARAJGI, B.. et al (1991) Dosage of haloperidol for schizophrenia. Archives of General Psychiatry. 48, 166-170.

SONI, S. D., SAMPATH, G., SHAH, A., et al (1992) Rationalizing neuroleptic polypharmacy in chronic schizophrenics: effects of changing to a single depot preparation. Acta Psychiatrica Scandinavica, 86. 354-359.

THOMPSON. C. (1994) The use of high-dose antipsychotic medication. British Journal of Psychiatry. 164, 448458.

VAN PUTten. T., Marshall, B. D., Liberman. R., et al (1993) Systematic dosage reduction in treatment-resistant schizophrenic patients. Psychopharmacology Bulletin. 29, 315-320.

WARNER, J. P., Slade, R. \& Barnes, R. E. (1995) Change in neuroleptic prescribing practice. Psychiatric Bulletin. 19. 237-239.

A. Thomas, Clinical Assistant, G. Katsabouris. Statistician, and *N. Bouras, Consultant Psychiatrist and Senior Lecturer, Division of Psychiatry and Psychology, UMDS, Guy's Hospital, London SE1 9RT

*Correspondence 